\title{
O gosto dialógico: Uma reflexão sobre o valor estêtico a partir de Mikhail Bakhtin
}

\section{Dialogical taste: Some thoughts about the aesthetic value in Mikhail Bakhtin}

Afonso Nilson Souza ${ }^{1}$ 


\section{Resumo}

O presente artigo reflete sobre questões relacionadas ao gosto como critério de partida para avaliação estética. Partindo da obra de estetas como Luigi Pareyson e Clement Greenberg, e de filósofos como Immanuel Kant e Mikhail Bakhtin, o texto traça paralelos entre as possibilidades de juízos universalizantes com os conceitos de dialogismo e ato responsável estabelecidos pelo filósofo russo em Estética da criação verbal e Para uma filosofia do ato responsável. A possibilidade dos juízos de valor são então analisados a partir dos conceitos de Ato Responsável e da compreensão emotivo-volitiva do objeto como singularidade concreta.

Palavras-chave: gosto; dialogismo; ato-responsável.

\section{Abstract}

The present article dwells upon questions related to taste as criteria from which aesthetic evaluation emerges. The aim is to draw parallels between the possibilities of universalizing judgments and the concepts of dialogism and responsible act, the latter understood in the terms proposed by Bakhtin in "Speech Gender and Other Late Essays" and "Toward a Philosophy of the Act". In order to do so, we take as a starting point the work of aesthetes such as Luigi Pareyson and Clement Greenberg, as well as the work of philosophers like Immanuel Kant and, of course, Mikhail Bakhtin. The possibilities of value judgments are then analysed in the light of the concepts of responsible act and emotional volitional comprehension of the object understood as concrete singularity.

Keywords: Aesthetic; taste; dialogism; responsible act
ISSN: 1414.5731

E-ISSN: 2358.6958

1 Doutorando em Teatro pela Universidade do Estado de Santa Catarina 
Quando questionado sobre o motivo pelo qual ia ao teatro, em um círculo de estudos acerca do público na VIII Jornada Internacional de Estudos Teatrais, em Blumenau, respondi quase que instintivamente: vou ao teatro porque gosto. Poderia ter dito que ia ao teatro porque me pagam para ver espetáculos; faz parte do meu trabalho; pela diversão, ou mesmo por inquietações filosóficas, políticas e estéticas. Mas a resposta simplista e subjetiva relacionada ao gosto pareceu-me tão mais breve, completa e honesta que não pude responder de outra maneira naquele momento. A primeira, imediata e previsível reação à resposta foi a menção à problemática do gosto como categoria, ou seu valor científico em uma discussão acadêmica. Em resumo, o gosto pode ser objetivo?

Em sua Analítica do belo, Kant analisa o juízo de gosto e suas correlações objetivas, universalizantes e estéticas dentro da Crítica do juízo. Para Kant, o gosto "é a faculdade-de-julgamento de um objeto ou de um modo-de-representação, por uma satisfação, ou insatisfação, sem nenhum interesse" (1974, p.309). A faculdade de julgar, então e a partir da filosofia kantiana, tenta ser estabelecida como critério racional de análise. O gosto, como constituinte das ferramentas de percepção, apresenta uma primeira capacidade de apreensão da realidade e, por conseguinte, de avaliação estética. O problema, segundo Kant, com o gosto como juízo estético é a dificuldade em se estabelecer juízos universais, visto que antes de postular conceitos, alude à adesão a partir das sensações.

Mas como prescindir das sensações para estabelecer juízos? Luigi Pareyson em Os problemas da estética questiona peremptoriamente sobre a possibilidade do crítico realizar seu trabalho sem fazer uso do gosto. Ele afirma que:

É precisamente do gosto que eles (os críticos) partem para encontrar o acesso à obra, do gosto eles extraem aquela sensibilidade que lhes adverte sobre a presença da poesia, no gosto encontram as condições de congenialidade que os introduz a determinadas formas de arte: o gosto é, com efeito, a espiritualidade de uma pessoa, ou de um período histórico, traduzida numa espera de arte, um modo de ser, viver, pensar, sentir, resolvido num concreto ideal estético, um sistema de afinidades eletivas em campo artístico (Pareyson, 1984, p.178).

Ainda sobre a pretensão em se atingir juízos universalizantes, Pareyson afirma que o gosto é um modo de estabelecer leituras de algo, interpretações, enquanto que os juízos para atingir a universalidade não têm necessidade de realçar categorias abstratas, visto que é suficiente a menção a "concreta e singular individualidade da obra". O esteta italiano afirma também que interpretação e juízos são indivisíveis, e que só se pode chegar a uma avaliação universal da obra de arte através da pessoalidade do gosto (Pareyson, 1984, p.180).

Se Pareyson admite que sem o gosto não se pode fazer crítica, há que se presumir uma certa objetividade no gosto, pois que o aleatório e imprevisível da análise individual e pessoal de cada um dificilmente poderia se tornar um consenso. Kant fala em Senso Comunis, mas não especificou exatamente como se daria uma avaliação lógica desse consenso. O influente crítico de arte americano Clement Greenberg, nesse sentido, fazendo as menções e reverencias naturais à estética kantiana contida na Crítica do juízo, afirma que sim, pode existir uma objetividade no gosto. Ele afirma 
em seu ensaio Pode o gosto ser objetivo que o tempo pode representar essa objetividade. O consenso sobre Shakespeare, Mozart, Bach, Rembrandt e outros artistas seria uma espécie de fluxo objetivo sobre a qualidade de uma obra através da permanência de sua magnitude perante à história e sua representatividade artística.

O problema em Greenberg é que demora muito para se ser objetivo perante uma obra. Como avaliar uma obra contemporânea utilizando esse critério? Esperando trezentos anos para ver se sua permanência comprova sua qualidade? É uma boa complementação às noções de senso comum apontadas por Kant (o próprio Greenberg se achava um continuador da estética kantiana), mas a necessidade de se pensar sobre o que se produz hoje é tão evidente quanto era na época de Shakespeare ou Mozart. Greenberg aponta algumas questões relevantes em sua busca por um juízo universalizante do gosto. Ele fala sobre comparações:

\footnotetext{
De um modo geral, o juízo estético significa encontrar matizes, gradações ou mesmo medidas - no entanto, sem uma precisão quantitativa, e sim com um sentido de comparação (e não há refinamento na sensibilidade estética sem a prática da comparação). A valoração estética pertence mais a ordem da apreciação e da ponderação do que a enunciação de um veredicto - ainda que, muitas vezes, soe forçosamente como um veredicto, simples e direto, ao ser expressa em palavras (Greenberg, 2013, p. 63).
}

Novas dificuldades apresentam-se. Neste sentido: que tipo de comparações poderíamos fazer para avaliar uma obra de acordo com o gosto de cada um? Comparar uma obra comprovadamente boa (talvez comprovada pela história, como sugere Greenberg) com uma ruim, e desse extrato traçar uma regra? Ou comparar obras de épocas diferentes? Complexo, ambivalente e nada prático, para não dizer pernicioso. Comparar então o olhar de cada um perante a mesma obra? Estabelecer critérios a partir dos parâmetros de leitura de vários observadores? Criar um ponto de contato entre leituras diversas? Parece-me impreciso, mas polifônico. Não conseguiremos fugir de Bakhtin para falar sobre isso, e talvez seja necessário entrar em algumas delongas.

Mikhail Bakhtin afirma, em Estética da criação verbal, que o vivenciamento interior e o todo da vida só podem ser experimentados concretamente e percebidos internamente através das categorias de percepção do eu-para-mim e do outro-paramim. O excedente da visão em relação ao outro é que condiciona a esfera de ativismo exclusivo, em que o conjunto das percepções-ações externas ou internas completam o outro no que ele não pode completar-se. É através dessas percepções-ações que se configura a contemplação estética, e esse "completar" se configura como uma contemplação ativa-eficaz, que não ultrapassa o âmbito do dado do outro, mas unifica e ordena esse dado (Bakhtin, 2010, p. 56-57).

O filósofo russo presume a necessidade estética absoluta do outro, do ativismo que vê, lembra, reúne, unifica e que é capaz de criar uma personalidade externamente acabada, embora tal personalidade não exista se o outro não a cria, já que a memória estética é produtiva, cria o homem exterior em um novo plano da existência. Ele estabelece, nesse sentido, que a ação artística se conclui a despeito do objetivo e do sentido onde estes deixam de ser as únicas forças motrizes do ativismo. Isso só 
é possível e justificável em face da ação da outra pessoa, quando o ato perceptivo a completa e conclui o horizonte atuante e desdobrado pelo objetivo coercitivo-necessário.

Para Bakhtin o pensamento situa o corpo inteiramente no mundo exterior como um objeto entre outros objetos, mas é incapaz de fazê-lo com uma visão efetiva, que não pode auxiliar o pensamento propiciando uma imagem adequada. Assim, o corpo enquanto elemento de auto-consciência é um conjunto de sensações orgânicas interiores, de necessidades e desejos reunidos em torno de um centro interior. O elemento externo é fragmentário, sem autonomia e plenitude, sendo percebido sempre através de um equivalente que o leva a pertencer à unidade anterior.

Para a contemplação estética, no entanto, essa cisão deve ser rompida, visto que o valor estético só se realiza no momento em que o contemplador está dentro do objeto contemplado, no momento em que ele vivencia a vida do objeto de dentro do próprio objeto, coincidindo extremamente. Dessa forma, o objeto estético configura-se como sujeito de sua própria vida interior, e é no plano dessa vida interior do objeto estético que se realiza o valor estético, o plano de uma consciência que se auto-vivencia.

Mas como vivenciar o todo estético da obra? Segundo Bakhtin, cada personagem expressa a si mesma, mas o todo da obra é uma expressão do autor. Disso decorre uma consideração fundamental: o fato de que vivenciar empaticamente com o autor não é vivenciar empaticamente sua vida interior (suas alegrias, seus sofrimentos, seus desejos) no sentido em que se vivencia empaticamente com uma personagem, mas vivenciar empaticamente com sua diretriz criadora para o objeto da representação, como co-criação. Embora essa co-criação não possa ser interpretada como vivenciamento empático, ou seja, também não pode ser interpretada como contemplação, pois o todo estético não se co-vivencia, mas é criado de maneira ativa tanto pelo autor como pelo contemplador, admiti-se dizer que o que o espectador co-vivencia é a atividade criadora do autor, não sua obra.

Para o teatro, entretanto, só se consegue imprimir alguma verossimilhança dentro da teoria da interpretação estética de Backhtin inventando inconscientemente e adicionando a posição do autor-contemplador. Por exemplo, no caso da empatia ocasionada pelo sofrimento, a situação vital do sofredor motivada de dentro pode desencadear um ato ético para a ajuda, a consolação ou uma reflexão cognitiva. $A$ compenetração deve ser seguida de um retorno a mim mesmo, ao meu lugar fora do sofredor, e só deste lugar material da compenetração poderá ser assimilado o ato ético, cognitivo ou estético.

Ou seja, embora o prazer estético seja um sentimento real, o vivenciamento empático dos sentimentos da personagem é apenas um sentimento ideal, e a atividade estética apenas começa quando retornamos a nós mesmos e ao nosso lugar fora da pessoa que sofre. A forma estética não pode ser fundamentada de dentro da personagem, de dentro de seu propósito semântico e material, de sua significação puramente vital. A forma é fundamentada no interior do outro, do autor como sua resposta criadora à personagem.

Bakhtin prossegue definindo o corpo exterior do homem integral, que é produto exclusivo do ponto de vista estético criador, como elemento esteticamente sig- 
nificativo e o mundo dos objetos como seu ambiente. Enquanto valor plástico, o homem exterior e o mundo que se correlaciona com ele e com ele se combina são "transgredientes" a sua autoconsciência possível e real, o eu-para-si, sua consciência vivente e vivenciadora. A interpretação estética e a estruturação do corpo exterior e seu mundo são uma "dádiva" de outra consciência - da consciência do autor-contemplador à personagem, não apenas uma atitude expressiva desta de dentro de si mesma, mas uma atitude criadora do autor-outro para com ela.

Assim, conclui Bakhtin em a Estética da criação verbal, que esse homem integral é produto de um ponto de vista estético criador e só deste. A cognição é indiferente aos valores e não apresenta um homem singular concreto. $O$ caráter ético, por princípio, pressupõe um sujeito esteticamente ativo, mas situado fora dele.

Mas ainda assim a questão sobre a possibilidade de uma categorização universal, um senso comum que pudesse ser objetivo, delimitável e catalogável permanece em aberto. E quem é esse sujeito esteticamente ativo de quem fala Bakhtin? Essas duas questões acabam ter conotações e desenvolvimento complementares em Para uma filosofia do ato responsável, onde o filósofo russo traça a oposição entre uma regra universal e a consciência individual.

Ao traçar uma linha divisória entre o imperativo categórico, sua subordinação a capacidade de ser universal, e o ato singular e sua capacidade de se tornar uma norma de comportamento geral, Bakhtin estabelece um choque de potências conceituais que estabelecem uma cisão entre conceitos universalizantes teóricos e a possibilidade de um consciência individual como ato-singular.

Um ato singular, para Bakhtin, configura-se como cada pensamento que se pode ter, e que compõe a vida como um agir ininterrupto, um ato complexo, sendo cada ato particular, cada experiência como um momento do viver-agir definido como uma vida singular. Em contraposição, a definição de um mundo teórico é obtida através de uma abstração que não leva em conta o fato dessa existência individual, dessa vida singular e o sentido moral que essa condição comporta.

Nesse sentido, o filósofo chega à conclusão de que não é possível nenhuma orientação prática da vida no mundo teórico, pois nele, por princípio o ser individual não tem lugar, não é necessário, e a possibilidade de um ato-responsável não é possível.

Como o ato-responsável, por sua vez, é definido como o ato que se realiza no interior da realidade prática vivida, e é baseado no reconhecimento de sua obrigatória singularidade e não repetibilidade, Bakhtin chega à conclusão que o ato-responsável se desenrola num existir único, e justamente por isso não é possível incluir o eu efetivo que o realiza como uma construção teórica, que se obtém através de construções de uma consciência teórica, ou abstração de um ato histórico individual.

Nesse contexto, considera-se que a apreensão de um objeto só se dá através de sua posse como unicidade real, mas tal unicidade só pode se dar com relação a singularidade do indivíduo, ou seja, um pensamento participativo, condição para o ato responsável, só pode existir através da compreensão emotiva-volitiva do objeto como singularidade concreta, de onde decorre o pensamento que age e se refere a si mesmo como ator responsável.

Ao se pressupor a arquitetônica de um mundo real, não enquanto pensado mas 
vivido, não abstrato mas como plano concreto do mundo do ato unitário singular, deve-se, segundo Bakhtin, descrever os momentos de sua construção através de pontos chave: eu-para-mim, o outro-para-mim e eu-para-o-outro. Disso decorre que todos os valores da vida real e da cultura se dispõe ao redor destes pontos arquitetônicos fundamentais. Valores estéticos, éticos, científicos, políticos e religiosos, bem como as relações de espaço e tempo, conteúdo-sentido tendem a esses momentos emotivos-volitivos centrais: o eu, o outro, o eu para o outro.

Com isso, o autor segue dizendo que mesmo com esses pontos primordiais para compreensão desses "valores", não existe um dever estético, científico e ético que se justifique como norma, pois há apenas o que é estética, teórica e socialmente válido como caráter técnico instrumental. Não existe uma norma moral válida em si, mas sim o sujeito moral com uma determinada estrutura, não psicológica ou física, mas em que se deve apoiar para saber em que consiste e quando deve cumprir o seu dever moral, ou mais especificamente, apenas o dever, já que não existe um dever especificamente moral.

Talvez em decorrência disso, quando Bakhtin afirma que cada valor que apresente validade geral só se torna realmente válido em um contexto singular, ele alude também a uma herança equivocada do racionalismo, onde se considera que a verdade só poderia ser universal, constituída de momentos gerais e consequentemente, reprodutível ou constante, enquanto a verdade individual é tida como artística e irresponsável, isolando-se em uma individualidade. E em contraponto a este equívoco apontado, afirma que o momento da atuação do pensamento, do sentimento, da palavra, de uma ação é precisamente a disposição ativamente responsável, emotivo-volitiva em relação à situação em sua totalidade, em um contexto real, unitário e singular.

O valor, então, do sentido sobre o plano abstrato pode ser encarnado apenas em uma situação concreta unitária, na qual se dá uma relação a um centro concreto de valores, sendo que a visão estética, também apresenta princípios de seleção arquitetonicamente (e não sistematicamente) subordinados ao centro valorativo de contemplação, no caso, o ser humano. Assim, ao invés de uma valoração que age através de uma consciência que busca justificação em um sistema, Bakhtin pressupõe que essa valoração procura sua justificação em uma realidade única e irrepetível, e que se contrapõe como individual perante todas as outras consciências, e emerge do interior do eu-individual enquanto a todos os outros é passível um encontro, onde o dever concreto, advindo do ato-responsável, é determinado antes de tudo como oposição valorativa entre ou eu e o outro.

\section{Referências}

BAKHTIN, Mikhail. Para uma filosofia do ato responsável. São Carlos. Pedro e João Editores: 2010. 
KANT, Immanuel. Crítica da razão pura e outros textos filosóficos. São Paulo. Editora Abril: 1974.

PAREYSON, Luigi. Os problemas da estética. São Paulo. Martins Fontes: 1984.

Recebido em: 04/12/2015

Aprovado em: 28/10/2016 